\title{
Benefícios da presença do acompanhante no processo de parto e nascimento: revisão integrativa
}

Benefits of the presence of a companion during the process of labor and delivery: integrative review Beneficios de la presencia del acompanãnte en el proceso de parto y nacimiento: revisión integradora

\section{Iris Elizabete Messa Gomes ${ }^{\mathrm{I}}$, Stela Maris de Mello Padoin ${ }^{\mathrm{II}}$, Tassiane Ferreira Langendorf ${ }^{\mathrm{III}}$ Cristiane Cardoso de Paula ${ }^{\mathrm{IV}}$, Cibele Avila Gomes ${ }^{\mathrm{V}}$, Aline Cammarano Ribeirov ${ }^{\mathrm{I}}$}

\begin{abstract}
Resumo: Objetivo: analisar as evidências científicas acerca dos benefícios da presença do acompanhante no processo de parto e nascimento. Método: revisão integrativa da literatura realizada no mês de abril de 2018, nas bases de dados Literatura Latino-Americana e do Caribe em Ciências da Saúde (LILACS), Base de Dados de Enfermagem (BDENF), Public Medline (PubMed), SCOPUS, utilizando estratégias de busca específicas para cada base. Foram selecionados 15 artigos para análise. Resultados: foram evidenciadas atividades desenvolvidas pelos acompanhantes que promoveram benefícios durante o processo de parto e nascimento como o apoio emocional, os laços familiares fortalecidos e a mudança de conduta profissional. Conclusão: para garantir a prática apoiada na evidência dos fatores benéficos é necessário ampliar ações institucionais e dos profissionais que viabilizem a efetiva participação do acompanhante no processo de parto e nascimento.
\end{abstract}

Descritores: Acompanhantes formais em exames físicos; Parto; Família; Enfermagem obstétrica; Saúde da mulher

Abstract: Objective: to analyze the scientific evidence about the benefits of the presence of a companion during labor and delivery. Method: Integrative literature review conducted in April 2018, in the Latin American and Caribbean Health Sciences Literature (LILACS), Nursing Database (BDENF), Public Medline (PubMed) and SCOPUS databases, using specific strategies to each database. Fifteen articles were selected for analysis. Results:

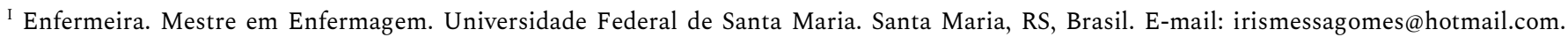
ORCID: https://orcid.org/0000-0002-0496-5892

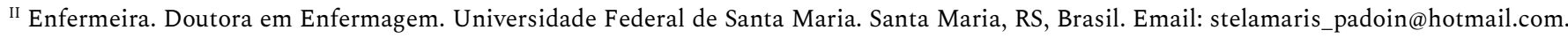
ORCID: https://orcid.org/0000-0003-3272-054X

III Enfermeira. Doutora em Enfermagem. Universidade Federal de Santa Maria. Santa Maria, RS, Brasil. Email: tassi.lang@gmail.com. ORCID: https://orcid.org/0000-0002-5902-7449

IV Enfermeira. Doutora em Enfermagem. Universidade Federal de Santa Maria. Santa Maria, RS, Brasil. Email: cris_depaula1@hotmail.com. ORCID: https://orcid.org/0000-0003-4122-5161

V Estudante de Medicina. Bolsista de Iniciação Científica. Universidade Federal de Santa Maria. Santa Maria, RS, Brasil. E-mail: cibegomes@gmail.com. ORCID: https://orcid.org/0000-0002-0740-5815

VI Enfermeira. Doutora em Enfermagem. Universidade Federal de Santa Maria. Santa Maria, RS, Brasil. Email: alinecammarano@gmail.com. ORCID: https://orcid.org/0000-0003-3575-2555
} 
Benefícios da presença do acompanhante no processo de parto e nascimento: revisão... | 2

practices developed by companions that promoted benefits during the process of labor and delivery were evidenced, such as emotional support, strengthened family bonds and change in professional conduct. Conclusion: in order to ensure the evidence-based practice of the beneficial factors it is necessary to expand institutional and professional actions that enable the effective participation of the companion in the process of labor and delivery.

Descriptors: Medical chaperones; Childbirth; Family; Obstetric nursing; Women's health

Resumen: Objetivo: analizar las evidencias científicas sobre los beneficios de la presencia del acompañante en el proceso de parto y nacimiento. Método: revisión integradora de la literatura realizada en abril de 2018, en las bases de datos Literatura Latino-Americana y del Caribe en Ciencias de la Salud (LILACS), Base de Datos de Enfermería (BDENF), Public Medline (PubMed), SCOPUS, utilizando estrategias de búsqueda específicas para cada base. Fueron seleccionados 15 artículos para análisis. Resultados: fueron evidenciadas actividades desarrolladas por los acompañantes que promovieron beneficios durante el proceso de parto y nacimiento como el apoyo emocional, el fortalecimiento de los lazos familiares y el cambio de la conducta profesional. Conclusión: para garantizar la práctica basada en la evidencia de los factores beneficiosos es necesario expandir las acciones institucionales y de los profesionales que permitan la participación efectiva del acompañante en el proceso de parto y nacimiento.

Descriptores: Chaperones Médicos; Parto; Familia; Enfermería Obstétrica; Salud de la Mujer

\section{Introdução}

As diretrizes nacionais ${ }^{1}$ e internacionais ${ }^{2}$ acerca da assistência ao parto normal recomendam a presença do acompanhante durante o parto e nascimento, sendo esta uma ação convergente à humanização da atenção à saúde neste momento. Essa perspectiva amplia-se nas discussões e prioridade nas ações de atenção à saúde obstétrica tendo em vista fortalecer as relações humanas envolvidas nesse processo, que tem se centrado na realização de intervenções e procedimentos. ${ }^{3}$ Assim, viabilizar e garantir a presença do acompanhante é considerada uma prática dignificante no cuidado à mulher durante o parto. ${ }^{4}$

A presença do acompanhante de livre escolha da mulher é reconhecida como uma das ações a ser aderida para as boas práticas na atenção ao parto normal, ${ }^{5}$ assegurada no Brasil pela Lei $11.108,{ }^{6}$ que a garante como um direito da parturiente, e pela Portaria 1.459 , que instituiu a Rede Cegonha. Esta se constitui como uma estratégia do Ministério da Saúde com a finalidade de estruturar e organizar a atenção à saúde materno-infantil no País, tendo em vista a implementação de uma rede de cuidados que contemple o direito ao planejamento reprodutivo e à atenção humanizada à gravidez, ao parto e ao puerpério. ${ }^{7}$ 
3 | Gomes IEM, Padoin SMM, Langendorf TF, Paula CC, Gomes CA, Ribeiro AC

Neste cenário, evidências apontam que as parturientes escolhem ter um acompanhante durante o parto e nascimento, sendo eles, na maioria das vezes, seu companheiro ou sua mãe..$^{8-9}$ Considerando as vivências neste momento, o acompanhante promove apoio nas esferas emocional e física, fazendo com que a mulher se sinta segura, caracterizando essa como uma prática indicada para todas as parturientes. ${ }^{10}$ Isso ratifica que a oferta da atenção obstétrica de qualidade significa, também, refletir acerca do envolvimento da família nos diferentes contextos de cuidado.

O apoio físico ou emocional ofertado pelo acompanhante da gestante no processo de parto e nascimento é uma prática segura e essencial para qualificar a atenção à saúde materna e neonatal, além de legitimar o direito das mulheres. ${ }^{10}$ No entanto, observa-se que o exercício e a garantia deste direito não ocorrem na totalidade dos partos e nascimentos, ${ }^{8-10}$ revelando que esta prática vem sendo implementada de maneira discreta e com enfrentamentos a serem vencidos.

Tendo em vista o exposto, questiona-se: "Quais são as evidências científicas acerca dos benefícios da presença do acompanhante no processo de parto e nascimento?”. Para responder à questão de pesquisa, este estudo objetivou analisar as evidências científicas acerca dos benefícios da presença do acompanhante no processo de parto e nascimento.

\section{Método}

Para atingir o objetivo proposto, optou-se por desenvolver uma pesquisa de revisão integrativa da literatura, ${ }^{11}$ visando analisar e sintetizar o conhecimento produzido acerca dos benefícios da presença do acompanhante no momento de parturição.

Foram seguidas as seguintes etapas: ${ }^{11}$ 1. Identificação do tema: presença do acompanhante no processo de parto e nascimento; 2 . Construção da questão de pesquisa com a estratégia PICO, ${ }^{12}$ constituída por P (população): acompanhantes, I (intervenção): presença do acompanhante, C (comparação): não se aplica e O (outcomes): benefício, definindo-se assim a 
Benefícios da presença do acompanhante no processo de parto e nascimento: revisão... $\mid 4$

seguinte questão: "Quais são as evidências científicas acerca dos benefícios da presença do acompanhante no processo de parto e nascimento?”; 3. Estabelecimento de critérios de inclusão: artigos de pesquisa desenvolvidos no Brasil (devido ao modelo de assistência obstétrico prestado e à política pública de saúde instituída no país), publicados nos idiomas português, inglês ou espanhol, no período entre 2005 e 2017, tendo em vista a criação da Lei do Acompanhante. ${ }^{6}$ A aplicação dos critérios de inclusão foi feita por duas pesquisadoras de forma dupla independente, a fim de garantir fidedignidade dos resultados; 4 . Definição das informações a serem extraídas dos estudos: referência, objetivo, delineamento, atividades desenvolvidas, benefícios da presença dos acompanhantes; 5. Avaliação das evidências e análise (categorização): o método utilizado para classificação da força de evidências propõe três tipos de questões, a saber: 1- Intervenção ou diagnóstico; 2- Prognóstico ou etiologia; 3- Significado, tendo como base a pergunta do estudo original. Em vista do corpus desta pesquisa, foi utilizada a classificação de evidências de estudos com questão clínica direcionada para o significado, com a seguinte hierarquia: I- Metassíntese de estudos qualitativos; II- Estudos qualitativos individuais; III- Síntese de estudos descritivos; IV- Estudos descritivos individuais; V- Opinião de especialistas; ${ }^{13}$ a análise dos dados foi realizada na forma descritiva com agrupamento por similaridade de evidência; 6. Discussão e apresentação da síntese do conhecimento.

Realizou-se a busca, em abril de 2018, nas bases de dados on-line: Literatura LatinoAmericana e do Caribe em Ciências da Saúde (LILACS), Base de Dados de Enfermagem (BDENF), Public Medline (PubMed) e SCOPUS.

Para a escolha dos descritores a serem utilizados na busca, foram realizadas consultas nos Descritores em Ciências da Saúde (DeCS) e no Medical Subject Headings (MeSH), e foram utilizadas palavras-chave a fim de localizar um maior número de evidências. Tendo em vista as especificidades das bases de dados, foram utilizadas estratégias de busca diferentes para cada uma delas, tendo como eixo norteador a questão de revisão e os critérios de inclusão (Tabela 1). 
5 | Gomes IEM, Padoin SMM, Langendorf TF, Paula CC, Gomes CA, Ribeiro AC

Tabela 1. Estratégias de busca utilizadas e produções selecionadas sobre os benefícios da presença do acompanhante no processo de parto e nascimento. LILACS, BDENF, PubMed, SCOPUS, 2005-2017. Fonte: Dados da pesquisa, Santa Maria/RS, 2018

\begin{tabular}{cccc}
\hline Bases & Estratégia de Busca & Publicações & Amostra \\
\hline LILACS & "Acompanhantes" OR "Familia" AND "parto" OR "Cesarea" & 669 & 13 \\
\hline BDENF & "Acompanhantes" OR "Familia" AND "parto" OR "Cesarea" & 188 & 02 \\
\hline Scopus & $\begin{array}{c}\text { "cesarean section" OR "natural childbirth" OR "labor, obstetric" } \\
\text { AND "medical chaperones" OR "social support" OR "labor } \\
\text { companionship" }\end{array}$ & 511 & - \\
\hline PubMed & "Cesarean section" OR "natural childbirth" OR "labor, obstetric" & 375 & - \\
\hline Total & AND "medical chaperones" OR "social support" & 1743 & 15 \\
\hline
\end{tabular}

Posterior à busca e aplicação dos critérios de inclusão, foram selecionados 15 artigos, que compuseram o corpus da pesquisa (Figura 1). A recuperação dos mesmos foi realizada pela própria base de dados e, quando não estavam disponíveis, buscou-se no Portal Capes e, após, no site das revistas.

Para o estabelecimento das informações a serem extraídas dos artigos, foi preenchido um quadro sinóptico, contemplando as seguintes informações: identificação do artigo, país onde o estudo foi realizado, subárea do conhecimento, objetivo, metodologia do estudo, acompanhantes, atividade desenvolvida e benefícios. Logo após foi realizada a análise das informações pertinentes para o alcance do objetivo da revisão. 
Benefícios da presença do acompanhante no processo de parto e nascimento: revisão... |6

Figura 1. Diagrama de Seleção dos estudos para revisão sobre os benefícios da presença do acompanhante no processo de parto e nascimento. LILACS, BDENF, PubMed, SCOPUS, 2005-2017. Fonte: Dados da pesquisa, Santa Maria/RS, 2018

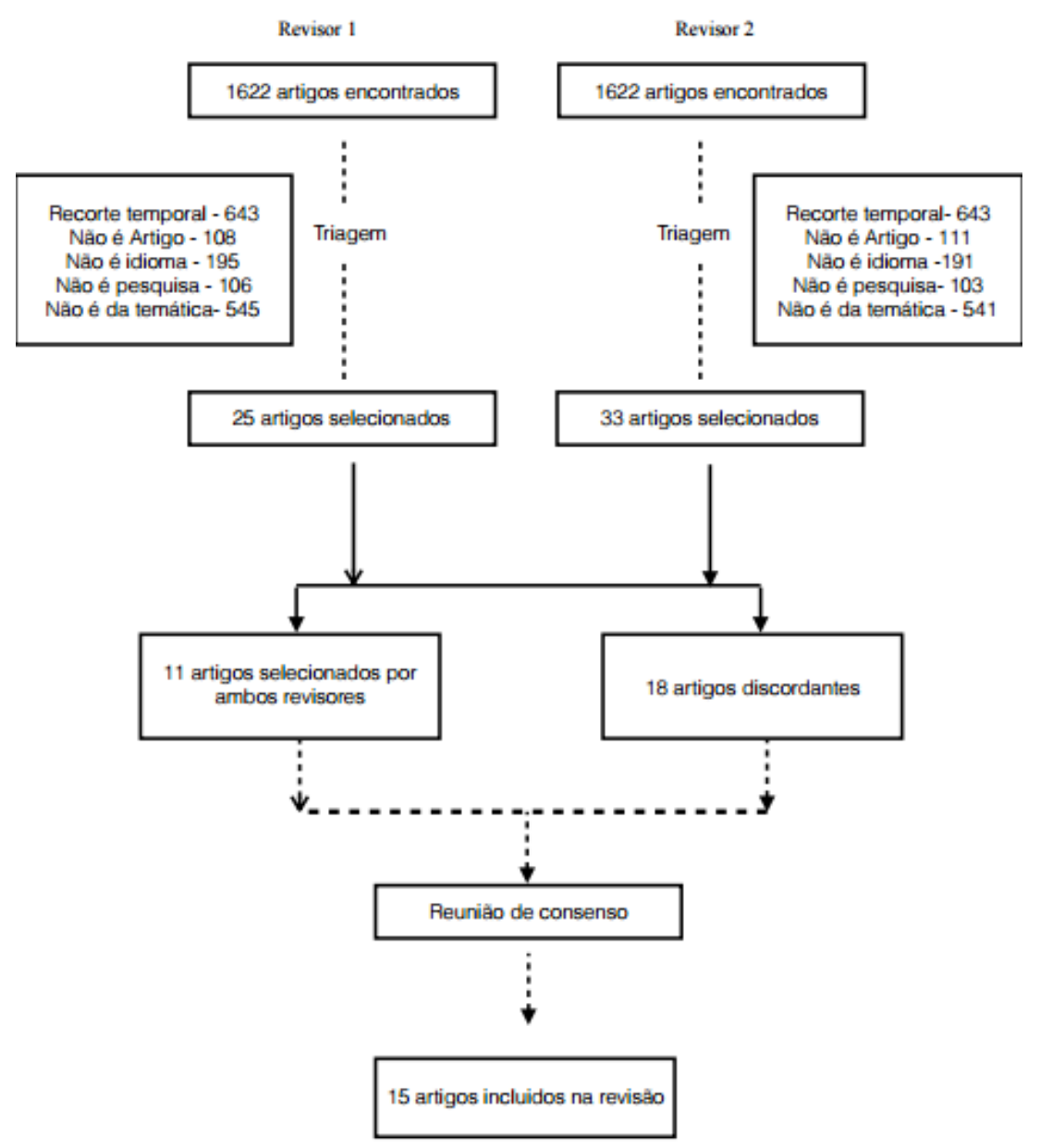

Foram respeitados os aspectos éticos das produções, assegurando ideias, conceitos e definições de autoria de cada artigo analisado, as quais estão apresentadas e referenciadas fidedignamente.

\section{Resultados}

A caracterização dos estudos analisados no que se refere à área do conhecimento, delineamento dos estudos, acompanhantes no momento do parto e níveis de evidência está 
7 | Gomes IEM, Padoin SMM, Langendorf TF, Paula CC, Gomes CA, Ribeiro AC

representada a seguir. Cabe salientar que, no que se refere aos acompanhantes no momento de parto, alguns estudos citaram mais de um acompanhante (Tabela 2).

Tabela 2. Caracterização dos artigos analisados sobre os benefícios da presença do acompanhante no processo de parto e nascimento. LILACS, BDENF, PubMed, SCOPUS, 2005-2017. Fonte: Dados da pesquisa, Santa Maria/RS, 2018

\begin{tabular}{|c|c|c|}
\hline & $\mathbf{N}$ & $\%$ \\
\hline \multicolumn{3}{|l|}{ Ano de publicação } \\
\hline 2011-2017 & 09 & 60,0 \\
\hline $2005-2010$ & 6 & 40,0 \\
\hline \multicolumn{3}{|l|}{ Abordagem metodológica da pesquisa } \\
\hline Quantitativo & 2 & 13,3 \\
\hline Qualitativo & 13 & 86,6 \\
\hline Acompanhantes & N de estudos que constavam & \\
\hline Marido/Companheiros/Pai do bebê/Esposo & 11 & - \\
\hline Mãe & 10 & - \\
\hline Irmã & 7 & - \\
\hline Sogra & 3 & - \\
\hline Cunhada & 4 & - \\
\hline Amiga & 2 & - \\
\hline Tia & 3 & - \\
\hline Comadre & 1 & - \\
\hline Outros (não especifica quem é o acompanhante) & 1 & - \\
\hline Total: & 15 & 100 \\
\hline
\end{tabular}

A distribuição temporal dos estudos foi agrupada de modo quinquenal e o período de 2011-2017 apresentou o maior número de produções, com 60\% (n = 09). Percebeu-se crescimento no número de artigos publicados nos últimos anos, demonstrando que a temática é cada vez mais explorada. Na abordagem metodológica predominaram estudos qualitativos, com $86,6 \%$ (n $=13)$.

Ainda, os estudos mostraram quem são os acompanhantes que estão presentes no momento do parto, dos quais se destaca a presença do marido ou do companheiro, em 11 estudos. Também foram citados como acompanhantes o pai do bebê, o esposo, a mãe, a irmã, a sogra, a cunhada, a amiga e outros. As informações extraídas dos estudos estão apresentadas no Quadro 1. 
Benefícios da presença do acompanhante no processo de parto e nascimento: revisão... $\mid 8$

\begin{tabular}{|c|c|c|c|c|}
\hline Autores & Objetivo & $\begin{array}{c}\text { Atividades desenvolvidas } \\
\text { pelos acompanhantes }\end{array}$ & $\begin{array}{l}\text { Benefícios da presença } \\
\text { do acompanhante }\end{array}$ & N.E. \\
\hline 总 & $\begin{array}{c}\text { Investigar a contribuição do } \\
\text { acompanhante durante o parto e } \\
\text { o nascimento, na perspectiva de } \\
\text { puérperas. }\end{array}$ & $\begin{array}{l}\text { Segurar a mão; oferecer } \\
\text { apoio; ajuda durante a } \\
\text { realização de exercícios; } \\
\text { realização de massagens. }\end{array}$ & $\begin{array}{l}\text { Gerar segurança, bem- } \\
\text { estar físico e confiança; } \\
\text { Amenizar a dor e a } \\
\text { sensação de solidão. }\end{array}$ & IV \\
\hline 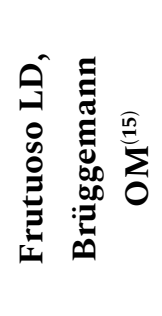 & $\begin{array}{l}\text { Conhecer quais informações os } \\
\text { acompanhantes possuem acerca } \\
\text { da Lei } 11.108 / 2005 \text {, as suas } \\
\text { percepções sobre a experiência } \\
\text { no centro obstétrico e as ações } \\
\text { de apoio junto à mulher. }\end{array}$ & $\begin{array}{l}\text { Acalmar; ficar ao lado; } \\
\text { Auxiliar na deambulação e } \\
\text { exercícios; realizar de } \\
\text { massagens; Segurar a mão. }\end{array}$ & $\begin{array}{c}\text { Companheirismo; } \\
\text { Valorização dos laços } \\
\text { familiares e da mulher. }\end{array}$ & IV \\
\hline 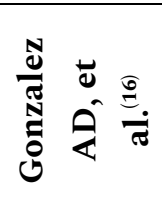 & $\begin{array}{l}\text { Conhecer a percepção do } \\
\text { acompanhante no processo do } \\
\text { nascimento. }\end{array}$ & $\begin{array}{c}\text { Ações de apoio para a } \\
\text { parturiente ficar calma e } \\
\text { tranquila; } \\
\text { Presença contínua; }\end{array}$ & $\begin{array}{l}\text { Fortalecer vínculos; } \\
\text { promover confiança e } \\
\text { tranquilidade; } \\
\text { Valorização da mulher }\end{array}$ & IV \\
\hline 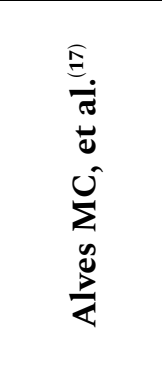 & $\begin{array}{l}\text { Compreender a inserção do } \\
\text { acompanhante no centro } \\
\text { obstétrico e identificar as ações } \\
\text { de apoio à parturiente } \\
\text { desenvolvidas no trabalho de } \\
\text { parto, parto e pós-parto } \\
\text { imediato. }\end{array}$ & $\begin{array}{c}\text { Presença contínua; } \\
\text { Massagens; Acompanhar } \\
\text { na deambulação, no banho, } \\
\text { nos exercícios; } \\
\text { Segurar a mão; explicar } \\
\text { procedimentos; Conversar. }\end{array}$ & $\begin{array}{l}\text { Fortalecer os laços } \\
\text { familiares; Antecipar o } \\
\text { primeiro contato do } \\
\text { recém-nascido com a } \\
\text { família; tranquilizar. }\end{array}$ & IV \\
\hline 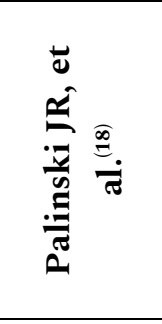 & $\begin{array}{l}\text { Procurou um entendimento da } \\
\text { percepção das mulheres sobre a } \\
\text { participação de um } \\
\text { companheiro, escolhido por elas, } \\
\text { durante o processo de trabalho } \\
\text { de parto. }\end{array}$ & $\begin{array}{l}\text { Suporte físico; presença } \\
\text { constante; segurar a mão. }\end{array}$ & Segurança; Tranquilidade; & IV \\
\hline 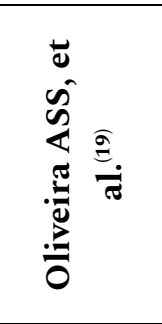 & $\begin{array}{l}\text { Analisar a percepção de } \\
\text { puérperas acerca da } \\
\text { presença/participação do } \\
\text { acompanhante durante o } \\
\text { trabalho de parto e o parto. }\end{array}$ & $\begin{array}{l}\text { Conversar; segurar a mão; } \\
\text { explicar procedimentos e } \\
\text { preocupar-se com o bebê. }\end{array}$ & $\begin{array}{l}\text { Amenizar a dor, o } \\
\text { sentimento de solidão e o } \\
\text { medo; confiança; } \\
\text { segurança; tranquilidade; } \\
\text { possibilidade de } \\
\text { comunicação }\end{array}$ & IV \\
\hline 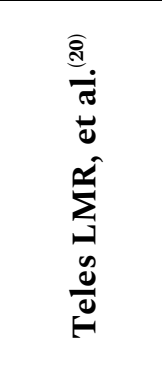 & $\begin{array}{l}\text { Descrever as atividades } \\
\text { desempenhadas pelo } \\
\text { acompanhante durante o } \\
\text { trabalho de parto e parto, além } \\
\text { de comparar a experiência com } \\
\text { acompanhante e sem } \\
\text { acompanhante. }\end{array}$ & $\begin{array}{l}\text { Presença constante; toque; } \\
\text { massagens; proporcionar } \\
\text { conforto; auxílio na } \\
\text { deambulação, no banho. }\end{array}$ & $\begin{array}{l}\text { Confiança; incentivo ao } \\
\text { parto normal. }\end{array}$ & IV \\
\hline
\end{tabular}




\begin{tabular}{|c|c|c|c|c|}
\hline 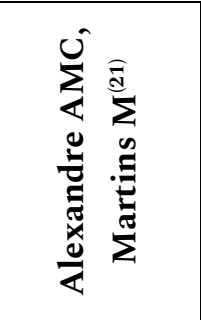 & $\begin{array}{l}\text { Conhecer a vivência dos pais em } \\
\text { relação ao trabalho de parto e } \\
\text { parto de sua esposa. }\end{array}$ & Conversar & $\begin{array}{c}\text { Fortalecer o vínculo } \\
\text { familiar e afetivo do pai } \\
\text { com o filho; Valorização } \\
\text { da mulher; } \\
\text { Tranquilidade; } \\
\text { Segurança }\end{array}$ & II \\
\hline 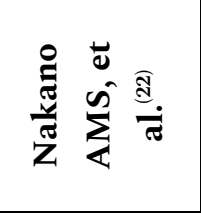 & $\begin{array}{l}\text { Compreender o significado do } \\
\text { ser acompanhante de uma } \\
\text { mulher em trabalho de parto e } \\
\text { parto. }\end{array}$ & $\begin{array}{l}\text { Ficar junto/ao lado; } \\
\text { observar tudo. }\end{array}$ & $\begin{array}{c}\text { Dar incentivo; } \\
\text { Tranquilizar e encorajar a } \\
\text { parturiente; Acalmar }\end{array}$ & II \\
\hline 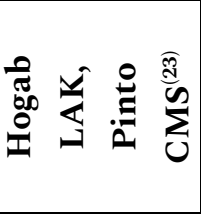 & $\begin{array}{c}\text { Descrever a experiência dos } \\
\text { membros da equipe profissional } \\
\text { relativa à presença do } \\
\text { acompanhante no parto. }\end{array}$ & Presença contínua & $\begin{array}{c}\text { Fortalecer vínculos } \\
\text { familiares; Segurança; } \\
\text { Tornar a assistência mais } \\
\text { afetuosa. }\end{array}$ & II \\
\hline 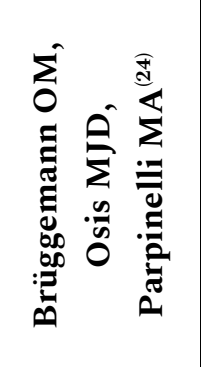 & $\begin{array}{c}\text { Descrever a percepção de } \\
\text { profissionais da saúde sobre } \\
\text { prestar assistência à parturiente } \\
\text { na presença do acompanhante } \\
\text { por ela escolhido, e a percepção } \\
\text { dos acompanhantes sobre essa } \\
\text { experiência. }\end{array}$ & $\begin{array}{c}\text { Segurar a mão; presença } \\
\text { constante; conversar }\end{array}$ & $\begin{array}{c}\text { Segurança, confiança e } \\
\text { colaboração; faz com que } \\
\text { o profissional tenha } \\
\text { atitude mais humana e } \\
\text { menos rotineira; auxilia } \\
\text { na evolução do parto. }\end{array}$ & II \\
\hline 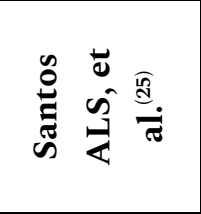 & $\begin{array}{l}\text { Compreender a percepção da } \\
\text { puérpera sobre a presença do } \\
\text { acompanhante durante o } \\
\text { trabalho de parto. }\end{array}$ & $\begin{array}{c}\text { Segurar a mão; Presença } \\
\text { contínua. }\end{array}$ & $\begin{array}{l}\text { Confiança e segurança; } \\
\text { minimiza sentimento de } \\
\text { solidão. }\end{array}$ & IV \\
\hline$\sum_{\substack{0 \\
0}}^{\substack{0 \\
0}}$ & $\begin{array}{l}\text { Averiguar a importância do } \\
\text { acompanhante durante o } \\
\text { processo de trabalho de parto na } \\
\text { perspectiva de puérperas. }\end{array}$ & $\begin{array}{l}\text { Conversar; realizar } \\
\text { massagens; presença } \\
\text { contínua. }\end{array}$ & $\begin{array}{c}\text { Segurança; ajuda a aliviar } \\
\text { as dores; valorização da } \\
\text { mulher pelos } \\
\text { companheiros; Fortalece } \\
\text { a unidade da família; } \\
\text { Diminui a solidão; } \\
\text { Facilitação do parto. }\end{array}$ & IV \\
\hline 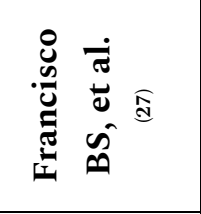 & $\begin{array}{l}\text { Conhecer as percepções do pai } \\
\text { acerca de sua vivência durante o } \\
\text { processo de nascimento do filho. }\end{array}$ & Massagens; segurar a mão & $\begin{array}{l}\text { Antecipa a criação de } \\
\text { vínculo entre pai e filho; } \\
\text { valorização da mulher; } \\
\text { Segurança. }\end{array}$ & IV \\
\hline 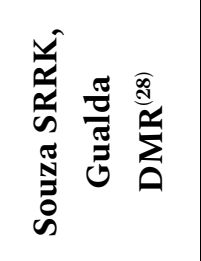 & $\begin{array}{l}\text { Conhecer a experiência de } \\
\text { mulheres e de seus } \\
\text { acompanhantes no processo de } \\
\text { parto. }\end{array}$ & $\begin{array}{l}\text { Massagem; Auxílio na } \\
\text { realização de exercícios; } \\
\text { Encorajar; Dar força; } \\
\text { Conversar; Presença } \\
\text { contínua. }\end{array}$ & $\begin{array}{c}\text { Acalmar; fortalecer } \\
\text { vínculo familiar; contato } \\
\text { precoce entre o pai e o } \\
\text { recém-nascido; } \\
\text { valorização da mulher. }\end{array}$ & II \\
\hline
\end{tabular}

Quadro 1. Quadro sinóptico das produções incluídas sobre os benefícios da presença do acompanhante no processo de parto e nascimento. LILACS, BDENF, PubMed, SCOPUS, 2005-2017. Fonte: Dados da pesquisa, Santa Maria/RS, 2018 
Benefícios da presença do acompanhante no processo de parto e nascimento: revisão... | 10

Quanto aos níveis de evidência, predominaram estudos com força de evidência IV, com 66,6\% ( $\mathrm{n}=10)$. A análise e síntese dos dados possibilitou a categorização de três fatores benéficos da presença do acompanhante no processo de parto e nascimento, bem como as atividades desenvolvidas pelos mesmos para proporcionar esses benefícios. Foram evidenciadas as atividades desenvolvidas pelos acompanhantes, bem como seus fatores benéficos: apoio emocional, laços familiares fortalecidos e mudança de conduta profissional (Tabela 3).

Tabela 3. Fatores benéficos e atividades desenvolvidas pelos acompanhantes no processo de parto e nascimento. LILACS, BDENF, PubMed, SCOPUS e Web of Science, 2005-2017. Fonte: Dados da pesquisa, Santa Maria/RS, 2018

\begin{tabular}{ll}
\hline & Fatores benéficos \\
\hline \multirow{2}{*}{ 1. Apoio emocional } & A parturiente se sente mais confiante ${ }^{(14,16,19-20,24-25)}$ \\
& ${\text { Segurança durante o processo de parturição }{ }^{(14,18,21,23-27)}}$ \\
& ${\text { Ameniza dor e sensação de solidão }{ }^{(14,19,25-26)}}$ \\
& Acalma/tranquiliza a parturiente ${ }^{(15-19,21-22)}$ \\
& Auxiliar da evolução fisiológica do trabalho de parto ${ }^{(17,20,23-24,26)}$ \\
\hline \multirow{2}{*}{ 2. Laços familiares fortalecidos } & ${\text { Contato precoce entre o pai/família e o } \mathrm{RN}^{(17,21,27-28)}}^{\text {Fortalecimento do vínculo familiar }^{(15-17,21,26,28)}}$ \\
\hline 3. Mudança na conduta profissional & Valorização da mulher $^{(15-16,21,27-28)}$ \\
\hline
\end{tabular}

Atividades desenvolvidas

Presença contínua ${ }^{(15-18,20,22-26,28)}$

Incentivador/Facilitador ao parto normal ${ }^{(17,20,23-24,26)}$

Auxílio nos exercícios ${ }^{(14,17,27-28)}$

Auxílio na deambulação ${ }^{(15,17,20)}$

Realização de Massagens (14-15,17,20,22,26,27,28)

Auxílio no banho ${ }^{(17,20)}$

Segurar a mão ${ }^{(14-15,17-19,24-25,27)}$

Conversar $^{(17,19,21,24,26,28)}$

Mediar a comunicação com a equipe ${ }^{(17,19,22)}$

\section{Discussão}

Os achados demonstram que diferentes atores sociais participam como acompanhantes da gestante durante o trabalho de parto e parto. Nos estudos foram mencionados pelo menos uma pessoa como acompanhante nesses momentos, dentre elas o pai da criança, o marido, o 
companheiro, a mãe, a irmã, a sogra ou os amigos. ${ }^{14-24,26,28}$ É possível pressupor que os acompanhantes são pessoas da rede social das parturientes.

O estudo realizado com 105 puérperas em uma maternidade-escola do Ceará evidenciou que a presença dos acompanhantes é muito importante, e justificou esse fato pelo apoio emocional, conforto físico e suporte de informações ofertados pelos acompanhantes ${ }^{20}$ e, neste sentido, a escolha destes é definida, na maioria das vezes, pelo vínculo que a gestante possui com determinada pessoa. ${ }^{25}$ Em algumas situações, a falta de acompanhamento ou a opção por alguém não tão próximo das mulheres em processo de parto e nascimento se dá pela impossibilidade de seu acompanhante de escolha estar presente, por motivos relacionados ao trabalho ou por necessitar cuidar dos demais filhos. ${ }^{14,19}$

Os fatores benéficos da presença dos acompanhantes podem ser observados a partir do apoio emocional ofertado, evidenciando que, quando a mulher está com um acompanhante, a mesma se torna mais confiante para o momento do parto. ${ }^{16,19-20,24-25}$ Isto está diretamente ligado do vínculo que a mulher possui com a pessoa escolhida, que a faz se sentir livre para verbalizar sentimentos que não se sente à vontade de dizer aos profissionais. ${ }^{20,24-25}$

As mulheres se sentem mais seguras ao contar com alguém de seu convívio para acompanhá-las durante o parto. ${ }^{14,18}$ A presença do acompanhante auxilia no processo fisiológico do parto, pois a mulher está segura de que tudo dará certo, visto que tem alguém em quem ela confia junto dela ${ }^{23-24,26}$ e que, se algo indesejado acontecer, ela não estará sozinha. ${ }^{14,26}$

O apoio emocional também ficou evidente nos estudos em que as mulheres ressaltaram que a presença do acompanhante pode amenizar a dor e a sensação de solidão..$^{14,19,25-26}$ Por ser um momento em que elas sentem medo, estar perto de alguém diminui a sensação de estar só ${ }^{19}$ e de passar por esse processo sozinha. Ainda, ao avaliar a experiência no pós-parto, as mulheres perceberam que, se estivessem sozinhas, o processo de parto e nascimento não teria acontecido da mesma forma, questionando-se se teriam conseguido. ${ }^{14}$ 
Benefícios da presença do acompanhante no processo de parto e nascimento: revisão... | 12

Acalmar a parturiente também foi elencado como um fator benéfico, considerando que o nervosismo por estar vivendo o desconhecido ou por estar em um ambiente estranho pode tornar o processo de parto e nascimento um momento de desagrado e desprazer. O fato de ter alguém do convívio ao seu lado implica, para a mulher, calma e tranquilidade. ${ }^{15-16,18}$ Ainda, outra atividade desenvolvida pela pessoa que acompanha o momento do trabalho de parto é conversar com a parturiente, ${ }^{19,26,28}$ trazendo à mulher conforto e tranquilidade pois, assim, ela se distrai e reafirma o sentimento de estar junto com alguém que a conhece e que é de sua confiança.

Explicar procedimentos que serão feitos também foi citado como atividade realizada pelo acompanhante, ${ }^{19,22}$ uma vez que, em situação de dor, as mulheres têm dificuldade em entender as orientações passadas pela equipe, e é neste momento que a pessoa que a acompanha é a mediadora e traduz essas informações de forma a torná-las de fácil entendimento para a mulher.

Transmitir as orientações dos profissionais de saúde para as mulheres em linguagem mais simples, que possibilite o entendimento da parturiente, ${ }^{17}$ torna-se um fator que incentiva e facilita o parto normal, pois, além de gerar nela sentimentos positivos, o que a deixa mais segura e colaborativa, também poderá ocasionar o aumento dos níveis de endorfina, o que reduz a dor e o estresse..$^{20,23-24}$

Diferentes estudos evidenciaram que a presença contínua do acompanhante pode acalmar, tranquilizar e motivar a mulher, ${ }^{15,17-18,20,22,24-25,28}$ sendo destacada como a principal atribuição do mesmo, ${ }^{23}$ e isso se manifesta pela demonstração de afeto e de companheirismo. ${ }^{17}$ Em estudo realizado em uma maternidade pública do Paraná, com 11 mulheres e 11 acompanhantes, os resultados demonstraram que as mulheres não deixavam, nem por um minuto, que o acompanhante se afastasse, visto que sua presença transmitia calma. ${ }^{28}$ Quando a acompanhante é outra mulher, esta, pautada em suas experiências prévias de parto, decide não deixar a parturiente sozinha, e evoca atributos maternos para que ela se sinta motivada. ${ }^{22}$ 
13 | Gomes IEM, Padoin SMM, Langendorf TF, Paula CC, Gomes CA, Ribeiro AC

Outro fator são os laços familiares que se fortalecem, na medida em que a pessoa que está vivenciando o momento do parto é alguém especial para a parturiente. É nesta hora que se tem o primeiro encontro entre a mulher, o bebê e a pessoa que ela escolheu para acompanhá-la, ${ }^{17}$ criando e fortalecendo laços familiares precocemente.

Nos estudos em que foi relatada a presença do pai no momento do nascimento, foi reforçado o compromisso entre este e sua companheira, uma vez que o parto é um momento de extrema intimidade, confiança e segurança. ${ }^{14,21,24}$ É nesse momento em que se tem o primeiro contato com o bebê, o primeiro colo e os primeiros cuidados, possibilitando ao pai que se sinta pertencente e participativo naquele momento. ${ }^{15-16,21,27} \mathrm{~A}$ valorização da mulher pelo seu companheiro e as consequências positivas no relacionamento foram percebidas nos relatos que mencionam que a mulher é a única pessoa capaz de passar pelo processo de parto e nascimento..$^{21,27-28}$

No que se refere ao fator benéfico de mudança na conduta profissional, ${ }^{23-24}$ ficou evidente que, ao prestarem assistência na presença de um acompanhante, os profissionais foram tocados por sentimentos de emoção e empatia, pois a convivência proporciona uma relação mais afetiva. ${ }^{23}$ Este profissional adota conduta de descentralização, não visando apenas o parto e o recém-nascido, mas a família, pois junto com a parturiente há alguém que se importa com ela. ${ }^{24}$

O apoio físico prestado às mulheres em processo de parto e nascimento se configurou como atividade de destaque. Os acompanhantes, ao realizarem atividades como deambular junto com a mulher, ${ }^{17,20}$ fazer massagens, ${ }^{14-15}$ acompanhá-la durante o banho ${ }^{17}$ e realizar os exercícios orientados pela equipe $e^{27-28}$ ou segurar a mão ${ }^{14,18-19,24-25}$ fazem com que a sua presença se torne benéfica, transmitindo confiança para a mulher e efeitos positivos na evolução do trabalho de parto.

\section{Conclusão}


Benefícios da presença do acompanhante no processo de parto e nascimento: revisão... | 14

Para além da garantia do direito ao acompanhante, os benefícios de estar acompanhada no processo de parto e nascimento promovem sentimentos de segurança e confiança. Esses benefícios implicam não só no processo fisiológico da evolução do parto, mas também no fortalecimento dos vínculos familiares, ao viabilizarem a aproximação e o contato do acompanhante com a mulher e o bebê logo após o nascimento.

Nas ações de atenção à saúde obstétrica, a lacuna do conhecimento evidenciada nesta revisão foi a modificação de conduta dos profissionais na atenção à saúde prestada, o que indica a necessidade de pesquisas com esse objeto de estudo. Como implicação para a prática, isso indica a necessidade em reconhecer o acompanhante como importante ator social no processo de parto e nascimento. Além disso, para garantir a prática apoiada na evidência dos fatores benéficos é necessário ampliar ações institucionais e dos profissionais que viabilizem a efetiva participação do acompanhante nesse processo.

Definiu-se para esta revisão a análise de estudos nacionais, não permitindo assim generalizações, e configurando este aspecto como uma limitação do estudo. Diante disso, considera-se importante o desenvolvimento de novas revisões que permitam ampliar a abrangência de estudos primários, inclusive no cenário internacional.

\section{Referências}

1. Ministério da Saúde (BR), Secretaria de Ciência, Tecnologia e Insumos Estratégicos. Diretriz Nacional de Assistência ao Parto Normal: relatório de recomendação. Brasília (DF): Ministério da Saúde; 2016.

2. World Health Organization (WHO). Care in normal birth: a practical guide. Geneva: WHO; 1996.

3. Aquino EML. Reinventing delivery and childbirth in Brazil: back to the future. Cad Saúde Pública [Internet]. 2014 [acesso em 2018 ago 02];30(Supl 1):S8-S3. Disponível em: http://www.scielo.br/scielo.php?script=sci_arttext\&pid=S0102-311X2014001300002

4. Silva ALS, Nascimento ER, Coelho EAC. Práticas de enfermeiras para promoção da dignificação, participação e autonomia de mulheres no parto normal. Esc Anna Nery Rev Enferm [Internet]. 2015 
[acesso em 2018 ago 02];19(3):424-31. Disponível em: http://www.scielo.br/pdf/ean/v19n3/1414-8145-ean19-03-0424.pdf

5. Carvalho EMP, Göttems LBD, Pires MRGM. Adherence to best care practices in normal birth: construction and validation of an instrument. Rev Esc Enferm USP [Internet]. 2015 [acesso em 2018 ago 02];49(6):890-8. Disponível em: http://www.scielo.br/scielo.php?script=sci_arttext\&pid=S008062342015000600889

6. Brasil. Lei n.11.108, de 07 de abril de 2005. Altera a Lei no 8.080, de 19 de setembro de 1990, para garantir às parturientes o direito à presença de acompanhante durante o trabalho de parto, parto e pósparto imediato, no âmbito do Sistema Único de Saúde - SUS [Internet]. 2005 [acesso em 2018 ago 02]. Disponível em: http://www.planalto.gov.br/ccivil_03/_Ato2004-2006/2005/Lei/L11108.htm

7. Brasil. Ministério da Saúde. Portaria 1.549, de 24 de junho de 2011. Institui no âmbito do Sistema Único de Saúde - SUS - a Rede Cegonha [Internet]. 2001 [acesso em 2018 ago 02]. Disponível em: http://bvsms.saude.gov.br/bvs/saudelegis/gm/2011/prt1459_24_06_2011.html

8. Gonçalves AC, Rocha CM, Gouveia HG, Armellini CJ, Moretto VL, Moraes BA. O acompanhante no centro obstétrico de um hospital universitário do sul do Brasil. Rev Gaúch Enferm [Internet]. 2015 [acesso em 2018 ago 02];36(N Esp):159-67. Disponível em: http://www.scielo.br/pdf/rgenf/v36nspe/0102-6933rgenf-36-spe-0159.pdf

9. Medeiros RMK, Texeira RC, Nicolini AB, Alvares AS, Corrêa ACP, Martins DP. Cuidados humanizados: a inserção de enfermeiras obstétricas em um hospital de ensino. Rev Bras Enferm [Internet]. 2016 [acesso em 2018 ago 02];69(6):1091-8. Disponível em:

http://www.scielo.br/pdf/reben/v69n6/0034-7167-reben-69-06-1091.pdf

10. Diniz CSG, d'Orsi E, Domingues RMSM, Torres JA, Dias MAB, Schnek CA, et al. Implementação da presença de acompanhantes durante a internação para o parto: dados da pesquisa nacional Nascer no Brasil. Cad Saúde Pública [Internet]. 2014 [acesso em 2018 ago 02];30(Supl):S140-53. Disponível em: http://www.scielo.br/pdf/csp/v30s1/0102-311X-csp-30-s1-0140.pdf

11. Ganong LH. Integrative reviews of nursing research. Res Nurs Health [Internet]. 1987 mar [acesso em 2018 ago 02];10(1):1-11. Disponível em: https://onlinelibrary.wiley.com/doi/abs/10.1002/nur.4770100103

12. Stillwell SB, Fineout-Overholt E, Mazurek B, Melnyk BM, Williamson KM. Searching for the Evidence: strategies to help you conduct a successful search. Am J Nurs [Internet]. 2010 jan [acesso em 2018 ago 02];110(1):51-3. Disponível em: https://insights.ovid.com/pubmed? pmid=20520115

13. Fineout-Overholt E, Stillwell SB. Asking compelling, clinical questions. In: Melnyk BM, FineoutOverholt E. Evidence-based practice in nursing \& healthcare: a guide to best practice. Philadelphia: Wolters Kluwer, Lippincott Williams \& Wilkins; 2011. p. 25-39. 
Benefícios da presença do acompanhante no processo de parto e nascimento: revisão... | 16

14. Dodou HD, Rodrigues DP, Guerreiro EM, Guedes MVC, Lago PN, Mesquita NS. Contribuição do acompanhante para humanização do parto: percepção das puérperas. Esc Anna Nery Rev Enferm [Internet]. 2014 [acesso em 2018 ago 02];18(2):262-69. Disponível em: http://www.scielo.br/pdf/ean/v18n2/1414-8145-ean-18-02-0262.pdf

15. Frutuoso LD, Brüggemann OM. Conhecimento sobre a lei 11.108/2005 e a experiência dos acompanhantes junto à mulher no centro obstétrico. Texto \& Contexto Enferm [Internet]. 2013 out-dez [acesso em 2018 ago 02];22(4):909-17. Disponível em: http://www.scielo.br/scielo.php?pid=S010407072013000400006\&script=sci_abstract\&tlng=pt

16. Gonzalez AD, Fernandes ES, Silva EF, Rabelo M, Souza SRRK. A percepção do acompanhante no processo do nascimento. Cogitare Enferm [Internet]. 2012 abr-jun [acesso em 2018 ago 02];17(2):310-4. Disponível em: https://revistas.ufpr.br/cogitare/article/view/27889

17. Alves MC, Brüggemann OM, Bampi RR, Godinho VG. The support of the companion choosen by the pregnant mother in a maternity school. Rev Pesqui Cuid Fundam [Internet]. 2013 jul-set [acesso em 2018 ago 02];5(3):153-64. Disponível em:

http://www.seer.unirio.br/index.php/cuidadofundamental/article/view/2060/pdf_835

18. Palinski JR, Souza SRRK, Rosa Gualda DMR, Silveira JTP, Salim NR. Women's perception of the process of labor coaching: study descriptive. Online Braz J Nurs [Internet] 2012. [acesso em 2018 ago 02];11(2):274-88. Disponível em: http://www.objnursing.uff.br/index.php/nursing/article/view/3603/html

19. Oliveira ASS, Rodrigues DP, Guedes MVC, Felipe GF, FT Galiza, Monteiro LC. O acompanhante no momento do trabalho de parto e parto: percepção de puérperas. Cogitare Enferm [Internet]. 2011 abr-jun [acesso em 2018 ago 02];16(2):247-53. Disponível em:

https://revistas.ufpr.br/cogitare/article/viewFile/20201/14211

20. Teles LMR, Pitombeira HCS, Oliveira AS, Freitas LV, Moura ERF, Damasceno AKC. Parto com acompanhante e sem acompanhante: a opinião das puérperas. Cogitare Enferm [Internet]. 2010 out-dez [acesso em 2018 ago 02];15(4):688-94. Disponível em: https://revistas.ufpr.br/cogitare/article/view/20366

21. Alexandre AMC, Martins M. A vivência do pai em relação ao trabalho de parto e parto. Cogitare Enferm [Internet]. 2009 abr-jun [acesso em 2018 ago 02];14(2):324-31. Disponível em: http://132.248.9.34/hevila/Cogitareenfermagem/2009/vol14/no2/14.pdf

22. Nakano AMS, Silva LA, Beleza ACS, Stefanello JG, Gomes, FA. O suporte durante o processo de parturição: a visão do acompanhante. Acta Paul Enferm [Internet]. 2007 [acesso em 2018 ago 02];20(2):1317. Disponível em: http://www.scielo.br/scielo.php?pid=S0103-21002007000200004\&script=sci_abstract

23. Hoga LAK, Pinto CMS. Assistência ao parto com a presença do acompanhante: experiências de profissionais. Inv Educ Enferm [Internet]. 2007 [acesso em 2018 ago 02];25(1):74-81. Disponível em: https://www.redalyc.org/articulo.oa?id=105215404008 
24. Brüggemann OM, Duarte MJ, Mary O, Parpinelli A. Apoio no nascimento: percepções de profissionais e acompanhantes escolhidos pela mulher. Rev Saúde Pública [Internet]. 2007 [acesso em 2018 ago 02];41(1):44-52. Disponível em: http://www.scielo.br/scielo.php?pid=S0034$89102007000100007 \&$ script=sci_abstract\&tlng=pt

25. Santos ALS, Oliveira ARS, Amorim T, Silva UL. O acompanhante no trabalho de parto sob a perspectiva da puérpera. Rev Enferm UFSM [Internet]. 2015 jul-set [acesso em 2018 ago 02];5(3):531-40. Disponível em: https://periodicos.ufsm.br/reufsm/article/view/17337

26. Teles LMR, Américo CF, Pitombeira HCS, Freitas LV, Damasceno AKC. Delivery accompanied in perspective from who has experience. Rev Enferm UFPE On Line [Internet]. 2010 [acesso em2018 ago 02];4(2):498-03. Disponível em: https://periodicos.ufpe.br/revistas/revistaenfermagem/article/view/6182

27. Francisco BS, Souza BS, Vitório ML, Zampieri MFM, Gregório VRP. Fathers' perceptions about their experiences as birth companions. REME Rev Min Enferm [Internet]. 2015 jul-set [acesso em 2018 ago 02];19(3):576-83. Disponível em: http://www.reme.org.br/artigo/detalhes/1024

28. Souza SRRK, Gualda DMR. A experiência da mulher e de seu acompanhante no parto em uma maternidade pública. Texto \& Contexto Enferm [Internet]. 2016 [acesso em 2018 ago 02];25(1):e4080014. Disponível em: http://www.scielo.br/scielo.php?pid=S010407072016000100309\&script=sci_abstract\&tlng=pt

\section{Autor correspondente}

Stela Maris de Mello Padoin

E-mail: stelamaris_padoin@hotmail.com

Endereço: Av. Roraima, n. 1000, prédio 26, sala 1336, Cidade Universitária, Bairro Camobi, Santa Maria, RS, Brasil. CEP: 97105-900

\section{Contribuições de Autoria}

\section{1 - Iris Elizabete Messa Gomes}

Concepção e planejamento da revisão, obtenção, análise e interpretação dos dados, redação e revisão crítica.

\section{2 - Stela Maris de Mello Padoin}

Concepção e planejamento da revisão, análise e interpretação dos dados, redação e revisão crítica.

\section{3 - Tassiane Ferreira Langendorf}

Análise e interpretação dos dados, redação e revisão crítica.

\section{4 - Cristiane Cardoso de Paula}

Concepção e planejamento da revisão, análise e interpretação dos dados, redação e revisão crítica. 
Benefícios da presença do acompanhante no processo de parto e nascimento: revisão... | 18

\section{5 - Cibele Avila Gomes}

Obtenção, análise, interpretação dos dados e redação.

\section{6 - Aline Cammarano Ribeiro}

Análise e interpretação dos dados, redação e revisão crítica.

\section{Como citar este artigo}

Gomes IEM, Padoin SMM, Langendorf TF, Paula CC, Gomes CA, Ribeiro AC. Benefícios da presença do acompanhante no processo de parto e nascimento: revisão integrativa. Rev. Enferm. UFSM. 2019 [Acesso em: Ano Mês Dia];vol.9 e61: 1-18. DOI:https://doi.org/10.5902/2179769234170 